\title{
Students' Continuance Intention to Experience Virtual and Remote Labs in Engineering and Scientific Education
}

\author{
https://doi.org/10.3991/ijet.v14i17.10799 \\ Muhua Zhang $(\bowtie)$ \\ China Three Gorges University, Yichang, China \\ zhangmuhua@etgu.edu.cn \\ Yanyan Li \\ Beijing Normal University, Beijing, China
}

\begin{abstract}
Virtual and Remote Labs (VRLs) had been widely used in Engineering and Scientific Education in recent years. The purpose of this study was to explore the students' satisfaction of VRLs and their continuance intention to experience VRLs in future study. The VRL developed by Unity3D PRO was integrated into an undergraduate course named "Introduction to computer science". 240 college students from China Three Gorges University took the course and had the virtual and remote laboratory experience for 16 weeks. Students' satisfaction and continuance intention were investigated by a three-part questionnaire based on the Expectation-Confirmation Model and Flow Theory. SPSS 19.0 was used for the quantitative analysis. The results indicated that the flow experience of students in VRL was at general level while the female students' perception of flow was higher than the males. Correlation analysis found that the flow experience had an extremely significant correlation with the students' perceived usefulness, confirmation, satisfaction and continuous intention. Stepwise regression analysis found that flow experience, perceived usefulness and satisfaction were all positive predictor of the students' continuance intention. Finally, some suggestions for integrating VRLs in engineering and scientific education were provided.
\end{abstract}

Keywords-Virtual and remote labs (VRLs), Expectation-Confirmation Model (ECM), Flow, Continuance Intention, Quantitative research

\section{Introduction}

As we all know, the experimentation played an important role in engineering and scientific education. With the rapid development of information and technology, new types of labs based on computer were emerging. According to the difference of experimentation environments, there were four types of labs: hands-on lab, a mono-user virtual lab, remote lab and multi-user virtual lab [1]. In the traditional hands-on lab, all the experimental resources were local accessed and the environments were real. In the 
mono-user virtual lab, the experimentation interface worked on a simulated, virtual and physically non-existent resource and the whole environment was software-simulated. In the remote lab, users were allowed to access the real plant equipment through the Internet and remotely operate the equipment through an experimentation interface. Different with the remote lab, users in the multi-user virtual lab operated with the experimentation interface on a virtual system on the Internet rather than the physical system. Besides, several users were allowed to operate simultaneously with the same virtual system in the multi-user virtual lab. Excluding the hands-on lab, the other three types were called Virtual and Remote Labs (VRLs) in general.

Compared with the hand-on lab, the VRLs not only enabled reducing costs, but also could be used safely from anywhere at anytime. Some empirical studies had shown that VRLs brought the same learning results with the traditional hands-on lab [2][3][4]. VRLs were an ideal tool to enable pre-laboratory preparation [5] and favor students' engagement into "what if" explorations where the outcomes of the virtual experiments could be immediately accessed [6]. Although there were many advantages of virtual labs, there were still some problems in virtual laboratory experience due to the nature of a virtual system. Compared with the real experience in hands-on lab, the students' attitude in virtual laboratory experience tended to be lack of seriousness, responsibility, and concentration [7]. Thus, it was essential to explore the application of VRLs in engineering and scientific education from the perspective of students' experience.

\section{The Related Studies}

Early studies of VRLs mainly focused on the approaches to build, manage, and share VRLs and the application of some particular VRLs in the specific discipline, such as control engineering, chemistry, mechanics. Harward et al. described the VRL architecture named iLab, which supported delivering VRLs for a potentially unlimited number of users as well as contributed to improve lab utilization levels, share costs, and increase the lab audience by supporting the cross-institutional sharing [8]. Lowe et al. introduced two architectures: iLab and UTS as well as analyzed their strengths and shortcomings of deploying and managing remote labs [9]. Dormido et al. described a VRL named the Three-Tank Plant, which was for experimentation on a nonlinear multiple-input-multiple-output system in Control engineering [10]. Koretsky et al. described a virtual lab for chemical vapor deposition processes with the purpose of engaging students in certain aspects of the experimental design, including the experimental strategy, the analysis and interpretation of data, and the iterative process of redesign [11]. Restivo et al. described a remote lab, which was developed with LabVIEW and deployed into Moodle, in order to measure and determine mechanical material characteristics [12].

A small number of previous studies also explored the collaborative learning in VRLs. van Joolingen et al. presented the learning environment Co-Lab, in which groups of learners could experiment through VRLs and express acquired understanding in a runnable computer model [13]. The study justified the importance of organizing science education around collaborative inquiry at the same time. Jara et al. explored an original approach for collaborative learning in VRLs through extending the Easy Java 
Simulations (EJS) authoring tool to provide synchronous interaction of multiple participants with a given VRL. Follow this way, any VRL created with EJS could transform the lab itself into a communication medium among learners as well as get automatically support for collaborative work [14]. Jara et al. also described the main features of the e-learning system based on VRLs, which was integrated inside a synchronous collaborative e-learning framework, and its successful application for science and engineering subjects [15].

Recently, a large number of study paid attention to assess the educational effectiveness of VRLs. Lindsay and Good used the calibration of a piezoelectric accelerometer to empirically compare the educational effectiveness of hands-on, remote, and virtual labs. According to their study, different types of labs were not equivalent in terms of learning outcomes as each modality had its own strengths and weaknesses [16]. Tzafestas et al. used a VRL in the field of robotics to compare the pedagogical effectiveness of hands-on, remote, and virtual labs. According to the experimental results, it seemed that virtual labs were as effective as remote and hands-on labs [17]. Nickerson et al. proposed a model for systematically testing the educational effectiveness of a given remote lab in terms of students' cognition and motivation [18]. Abdulwahed and Nagy described an empirical study to measure the pedagogical effectiveness of hands-on lab and VRLs to support the Kolb's learning cycle, which confirming that VRLs were effective to activate the apprehension dimension of Kolb's cycle and an effective supplement to hands-on labs [19]. According to Kolloffel and Jong's study, students in the virtual lab condition acquired better conceptual understanding and developed better procedural skills than those in the traditional hand-on labs in engineering curricula about electrical circuits [20]. Marques et al. presented the results of integrating the open remote laboratory VISIR into several courses and found that VISIR were always of benefit for more motivated students when it was properly integrated into a course [21]. Garcia-Zubia et al. also integrated VISIR in teaching Analog Electronics and confirmed that the remote lab were able to produce a positive effect in students' learning if an appropriate learning activity was used [22].

However, few studies explored the application of VRLs in engineering and scientific education from the students' viewpoint. Raman et al. investigated potential-adopter students' perceptions of Virtual Lab as a multi-institutional Open Educational Resources (OER) initiative, using Roger's theory of perceived attributes [23]. Koretsky et al. compared students' perceptions of key cognitive processes and specific content afforded by an industrially situated virtual laboratory project and two physical laboratory projects through a free-response survey questions and content analysis [24]. Above studies didn't address the students' satisfaction and continuance intention of the VRLs. Thus, the study aimed at understanding the students' experience of VRLs and exploring the potential predictors of continuance intention of VRLs in engineering and scientific education. 


\section{Theoretical Basis}

Students' satisfaction and continuance intention of VRLs was very important to the implement of the online experimental teaching. Because the nature of the VRLs was a kind of information system (IS), students' satisfaction and continuance intention was similar to consumers' satisfaction and repurchase decision. Then, Bhattacherjee's Expectation-Confirmation Model (ECM) was used to examine students' satisfaction and continuance intention in this study.

Besides, students' engagement in VRLs was actually the process of completing a series of challenging tasks during the computer-mediated environment (CME), in which flow was easily emerging. What's more, according to Shin's study, flow was a significant predictor of students' satisfaction in an online virtual course [25].

Based on above evidence, the ECM and flow theory were integrated in the present study to examine the students' satisfaction and continuance intention of VRLs.

\subsection{Expectation-confirmation model (ECM)}

The ECM was based on expectation-confirmation theory, which was widely used in the consumer behavior literature to study consumers' satisfaction, post-purchase behavior [26]. There were four factors in ECM: Perceived usefulness, Confirmation, Satisfaction, and Continuance intention. According to Bhattacherjee, Perceived usefulness referred to users' perception of the expected benefits of IS use. Confirmation referred to users' perception of the congruence between expectation of IS use and its actual performance. Satisfaction referred to users' affect with prior IS use. Continuance intention referred to users' intention to continue using IS. Bhattacherjee's study found that users' continuance intention of IS was determined by their satisfaction with IS use and perceived usefulness of continued IS use as well as users' satisfaction was influenced by confirmation of expectation from prior IS use and perceived usefulness [27].

\subsection{Flow theory}

Csikszentmihalyi coined the term "Flow" and defined it as the holistic sensation that people feel when they act with total involvement [28]. According to Trevino and Webster, flow was an important element of understanding human-technology interactions, and indeed, an important antecedent of attitudes toward technologies [29]. Shin's study found that flow was conceptualized as a complex, multinational, reflective construct composing of 'enjoyment', 'telepresence', 'focused attention', 'engagement' and 'time distortion' on the part of learners in online learning environment [30]. Esteban-Millat's study further found that time distortions and focused attention were the most important direct antecedents of flow in virtual learning environment [31]. Thus, time distortions and focused attention were examined in this study to reflect the students' status of flow in experiencing VRLs. 


\section{$4 \quad$ Purposes and Objectives}

The purpose of this study was to explore the students' satisfaction and continuance intention of VRLs in an undergraduate course named "Introduction to computer science." We were especially interested in seeking answers for two questions:

- How did the students think of VRLs?

- Which factors will affect their perception of VRLs experience?

Specifically, the study had three primary objectives:

- Profiling participating students' flow experience in VRLs and their perception of VRLs experience.

- Exploring the correlation between the flow experience and the students' perception of their VRLs experience.

- Examining the predictors of students' continuance intention of VRLs.

\section{$5 \quad$ Methods}

\subsection{VRL used in this study}

The research team at the Beijing Institute of Technology developed the VRL used in this study. All the virtual experiments were designed with Unity3D PRO (education version), which is a virtual reality, cross-platform application development engine. The type of lab used in the present study was multi-user virtual lab, which allowed the students operate with the experimentation interface on a virtual system on the Internet as well as several users operate simultaneously with the same virtual system.

The VRL was available at http://www.vrsygc.com/index. Users need to register on the platform and join in the course in order to experience the virtual experiments. So, the online experimental class was created on the platform at the beginning of the course with the cooperation of the research team at the Beijing Institute of Technology. Seven virtual experiments were selected for the students to experience according to the course contents. Table1 showed the detailed information of the selected virtual experiments.

Table 1. The information of selected virtual experiments

\begin{tabular}{|l|l|l|}
\hline \multicolumn{1}{|c|}{ Name } & \multicolumn{1}{c|}{ Type } & Difficulty level \\
\hline Computer hardware virtual disassembly & Demonstration & low \\
\hline $\begin{array}{l}\text { Chinese character information coding and transformation in com- } \\
\text { puter }\end{array}$ & Authentication & medium \\
\hline The execution of an instruction in computer & Authentication & high \\
\hline Turing model demonstration & Demonstration & high \\
\hline File management virtual experiment & Authentication & low \\
\hline Image coding virtual experiment & Design & medium \\
\hline Firewall principle demonstration & Demonstration & low \\
\hline
\end{tabular}


Each experiment was equipped with an experimentation interface and an experimentation report interface. In the experimentation interface, just as Fig. 1 shown, the experimentation purpose, experimentation content, and experimentation operation tips were provided with detailed written words.

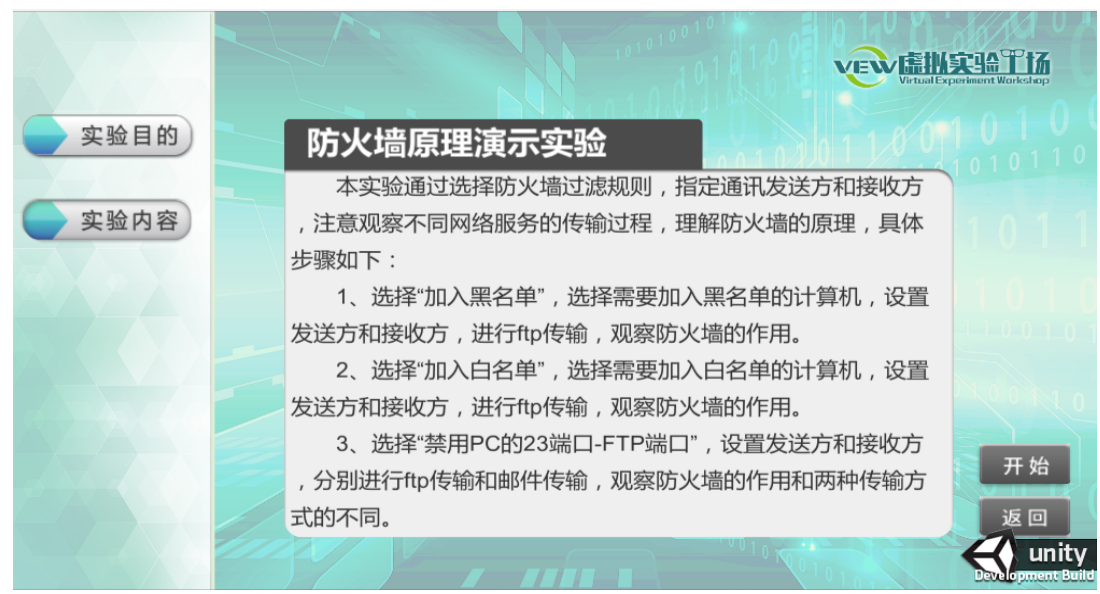

Fig. 1. The experimentation interface of firewall principle demonstration

As Fig. 2 shown, when the start button was clicked, the experimentation process was shown in an interactive animation.

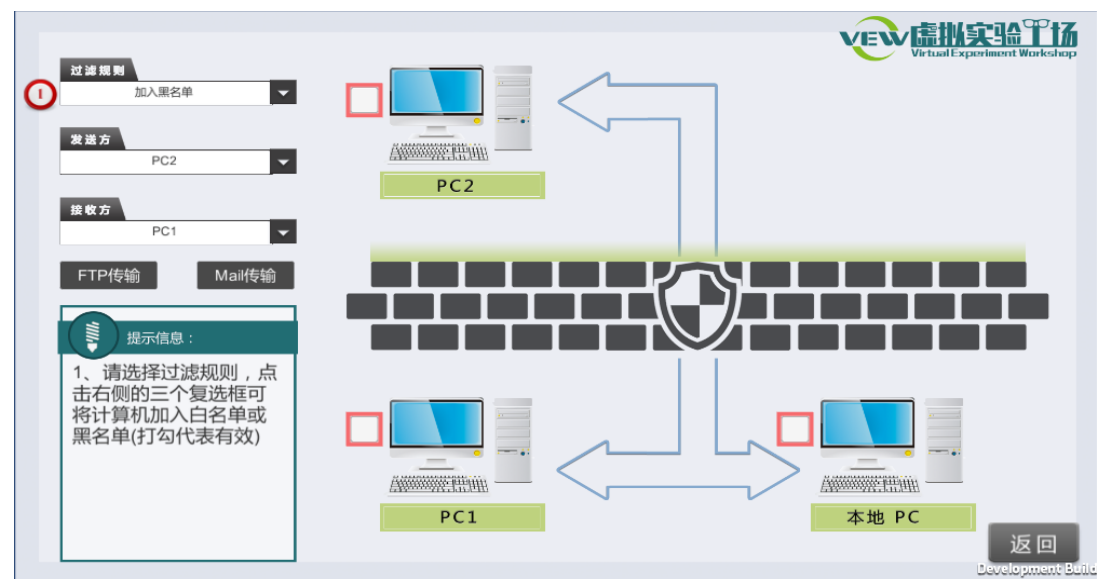

Fig. 2. The experimental process of firewall principle demonstration

Students could gradually complete the experiment according to the guidance information. After completing the experiment, the students need fill in the experimentation report and submit online. Each report was allowed to try no more than 10 times and no more than 40 minutes each time. The feedback on experimentation reports was 
instantaneous and automatic. Students were able to conduct the experiment again according to the feedback information until the experimentation report was completely correct.

\subsection{Participants}

240 college students joined in the course and had the virtual and remote laboratory experience during the Fall Semester in 2018. 238 of them participated the final investigation at the end of the course. 151(63\%) of them were male and 87(37\%) were female. The students were from six different major of the science and engineering, including Mechanical engineering (78, 33\%), Nuclear Engineering (15, 6\%), Energy Engineering (22, 9\%), Information and Computing Science (24, 10\%), Optoelectronic Information Science (40, 17\%), Electrical Engineering and Automation (59, 25\%). The age of the students were range from 17 to 21 . Among the participants, 115 students had the online learning experience before taking this course as well as 118 of them didn't have.

\subsection{Instruments}

Base on ECM and flow theory, a three-part questionnaire was developed as the research instrument. The first part of the questionnaire aimed at gathering participants' personal characteristics, including: gender, age, major and online learning experience. The second part was designed to examine the students' flow experience from two aspect: time distortion and focused attention. The third part came from the EMC and was adapted according to the present study. As indicated in Table 2, the final questionnaire consists of five subscales.

Table 2. The subscale and source of the questionnaire

\begin{tabular}{|l|c|l|}
\hline \multicolumn{1}{|c|}{ Factor names } & Number of items & \multicolumn{1}{c|}{ Source } \\
\hline Flow experiences(FE) & 4 & Esteban-Millat et al. (2014) \\
\hline Perceived usefulness(PU) & 3 & Bhattacherjee (2001) \\
\hline Confirmation(C) & 3 & Bhattacherjee (2001) \\
\hline Satisfaction(S) & 3 & Bhattacherjee (2001) \\
\hline Continuance intention(CI) & 3 & Bhattacherjee (2001) \\
\hline
\end{tabular}

Participants were asked to indicate their perceptions of the VRLs by responding to above sixteen statements on a five-point Likert scale from strongly disagree to strongly agree: 1 = strongly disagree; $3=$ neutral; and $5=$ strongly agree.

\subsection{Data collection and analysis}

Data were collected at the end of the course with the anonymous survey. All participants were provided with written information introducing the purpose of the survey. 238 useful surveys were returned and the response rate was about $99 \%$.

Data were compiled and analyzed using the Statistical Package for Social Sciences (SPSS19.0). Reliability was examined using Cronbach's $\alpha$ values for each variable: 
Flow experiences, 0.730; Perceived usefulness, 0.859; Confirmation, 0.835; Satisfaction, 0.857; Continuance intention, 0.908. Obviously, Cronbach's $\alpha$ values of each variable were all above 0.7 , which is a commonly acceptable level.

Descriptive statistics were used to describe each variable. Independent sample t test was used to examine the relationships between students' personal characteristics and their perception about the VRLs experience. Correlation analysis was used to examine the relationships between the students' flow experience and other variables. Stepwise regression analysis was used to explore the potential factors that affect the students' continuance intention. Alpha value for all statistical procedures was set a priori at .05.

\section{$6 \quad$ Findings}

\subsection{Students' flow experience and perception of VRLs experience}

The descriptive information of the students' flow experience and their perception of VRLs experience was indicated in Table 3.

Table 3. Descriptive infomation of each factor

\begin{tabular}{|l|c|c|c|c|}
\hline Factor names & Mean & SD & Min & Max \\
\hline FE & 3.64 & 0.62 & 1 & 5 \\
\hline PU & 3.85 & 0.68 & 1 & 5 \\
\hline C & 3.64 & 0.70 & 1 & 5 \\
\hline S & 3.61 & 0.75 & 1 & 5 \\
\hline CI & 3.66 & 0.76 & 1 & 5 \\
\hline
\end{tabular}

Generally speaking, the students' perception about above five aspects kept between neutral attitudes and agree attitudes, more likely to agree. The students' perception of usefulness was slightly higher than the other factors.

The study further examined the difference of students' perception about the VRLs experience by gender.

Table 4. Students' perception about the VRLs experience by gender

\begin{tabular}{|c|c|c|c|c|c|c|c|}
\hline & Gender & $\mathbf{N}$ & $\mathbf{M}$ & SD & DF & 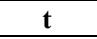 & $\mathbf{P}$ \\
\hline \multirow{2}{*}{ FE } & Male & 151 & 3.58 & 0.62 & \multirow{2}{*}{183.11} & \multirow{2}{*}{$-1.98^{*}$} & \multirow{2}{*}{.049} \\
\hline & Female & 87 & 3.74 & 0.61 & & & \\
\hline \multirow{2}{*}{ PU } & Male & 151 & 3.77 & 0.69 & \multirow{2}{*}{236} & \multirow{2}{*}{$-2.42^{*}$} & \multirow{2}{*}{.016} \\
\hline & Female & 87 & 3.99 & 0.63 & & & \\
\hline \multirow{2}{*}{$\mathrm{C}$} & Male & 151 & 3.54 & 0.69 & \multirow{2}{*}{236} & \multirow{2}{*}{$-2.91^{* *}$} & \multirow{2}{*}{.004} \\
\hline & Female & 87 & 3.81 & 0.69 & & & \\
\hline \multirow{2}{*}{$\mathrm{S}$} & Male & 151 & 3.52 & 0.74 & \multirow{2}{*}{181.16} & \multirow{2}{*}{$-2.62^{*}$} & \multirow{2}{*}{.010} \\
\hline & Female & 87 & 3.78 & 0.73 & & & \\
\hline \multirow{2}{*}{ CI } & Male & 151 & 3.55 & 0.76 & \multirow{2}{*}{181.53} & \multirow{2}{*}{$-2.80^{* *}$} & \multirow{2}{*}{.006} \\
\hline & Female & 87 & 3.83 & 0.75 & & & \\
\hline
\end{tabular}

*Correlation is significant at $\mathrm{p}<.05 . ; *$ Correlation is significant at $\mathrm{p}<.01$. 
Just as table 4 shown, female students' perception about VRLs experience were better than males. Gender had a significant impact on both the students' flow experience, perceived usefulness and satisfaction at .05 level. Gender had an extremely significant impact on confirmation and continuance intention at .01 level.

The study also examined the difference of students' perception about the experience of VRLs by the online learning experience. As indicated in table5, independent sample $t$ test found that the online learning experience had significant impact on the confirmation while had no significant impact on the other variables. Besides, both age and major had no significant impact on the students' perception about the experience of VRLs.

Table 5. Students' perception about the VRLs experience by online learning experience

\begin{tabular}{|c|c|c|c|c|c|c|c|}
\hline & Online learning experience & $\mathbf{N}$ & $\mathbf{M}$ & SD & DF & $\mathbf{t}$ & $\mathbf{P}$ \\
\hline \multirow{2}{*}{$\mathrm{FE}$} & Yes & 115 & 3.68 & 0.63 & \multirow{2}{*}{231} & \multirow{2}{*}{0.81} & \multirow{2}{*}{.417} \\
\hline & No & 118 & 3.61 & 0.61 & & & \\
\hline \multirow{2}{*}{ PU } & Yes & 115 & 3.92 & 0.66 & \multirow{2}{*}{231} & \multirow{2}{*}{1.38} & \multirow{2}{*}{.169} \\
\hline & No & 118 & 3.79 & 0.69 & & & \\
\hline \multirow{2}{*}{$\mathrm{C}$} & Yes & 115 & 3.75 & 0.68 & \multirow{2}{*}{231} & \multirow{2}{*}{$2.33^{*}$} & \multirow{2}{*}{.021} \\
\hline & No & 118 & 3.54 & 0.70 & & & \\
\hline \multirow{2}{*}{$\mathrm{S}$} & Yes & 115 & 3.68 & 0.77 & \multirow{2}{*}{231} & \multirow{2}{*}{1.11} & \multirow{2}{*}{.270} \\
\hline & No & 118 & 3.57 & 0.72 & & & \\
\hline \multirow{2}{*}{$\mathrm{CI}$} & Yes & 115 & 3.74 & 0.80 & \multirow{2}{*}{231} & \multirow{2}{*}{1.55} & \multirow{2}{*}{.154} \\
\hline & No & 118 & 3.59 & 0.72 & & & \\
\hline
\end{tabular}

*Correlation is significant at $\mathrm{p}<.05$.

\subsection{Correlation analysis}

Correlation analysis was used to examine the relationships between students' flow experience and their attitude to the experience of VRLs.

Table 6. Correlation analysis of flow experience and other variables

\begin{tabular}{|l|l|c|c|c|c|}
\hline & & PU & C & S & CI \\
\hline \multirow{4}{*}{ FE } & Pearson correlation & $.575^{* *}$ & $.605^{* *}$ & $.597^{* *}$ & $.602^{* *}$ \\
\cline { 2 - 6 } & Sig. (2-tailed) & .000 & .000 & .000 & .000 \\
\cline { 2 - 6 } & $\mathrm{N}$ & 238 & 238 & 238 & 238 \\
\hline
\end{tabular}

$* *$ Correlation is significant at $\mathrm{p}<.01$.

As table 6 shown, the flow experience had an extremely significant correlation with the students' perceived usefulness, confirmation, satisfaction and continuous intention of the VRLs. The better the students' flow experience was, the stronger their perceived on usefulness, confirmation, satisfaction and continuous intention was.

\subsection{Stepwise regression analysis}

In this study, the flow experience, perceived usefulness, confirmation and satisfaction were processed as the predictors, while the continuance intention was the outcome variable. The outcome of stepwise regression analysis was indicated in table 7 . 
Table 7. Stepwise regression analysis of the continuance intention

\begin{tabular}{|l|c|c|c|c|c|}
\hline & $\mathbf{B}$ & S.E. & $\boldsymbol{\beta}$ & $\mathbf{T}$ & \multirow{2}{*}{$\mathbf{R}^{\mathbf{2}}$} \\
\hline FE & 0.16 & 0.06 & 0.13 & $2.73^{* * *}$ & \multirow{2}{*}{0.70} \\
\cline { 1 - 5 } PU & 0.33 & 0.06 & 0.29 & $5.56^{* * *}$ & \\
\hline S & 0.53 & 0.06 & 0.52 & $9.63^{* * *}$ & \\
\hline
\end{tabular}

**Correlation is significant at $\mathrm{p}<.001$.

As indicated in table 7, students' satisfaction played the most powerful role for predicting their continuance intention. The more satisfied the students' felt, the stronger their continuance intention was. The the perceived usefulness also played important role for predicting the students' continuance intention. The more the students' perceived usefulness was, the stronger their continuance intention was. What's more, flow experience can also positively predict the students' continuance intention. The better the students' flow experience was, the stronger their continuance intention was. Confirmation couldn't predict the students' continuance intention according to the stepwise regression analysis.

\section{Discussion}

Firstly, the study found that the flow experience of students in virtual experimental learning was at general level while the female students' perception of flow was higher than the males. According to the flow theory, when the individual's skill level matched with the challenge level of the task, the flow would appear. In the present study, virtual experiments of different difficulty levels were provided for all the students. However, the challenge level of the experiments could not match each student's skill level, which resulted to the students' flow experience was at general level. Presumably, the challenge level of the experiments was more suitable for the female students.

The study also found that the students' attitude to the virtual experimental experience kept between neutral attitudes and agree attitudes, more likely to agree. Gender had a significant impact on both the students' perceived usefulness, satisfaction, confirmation and continuance intention. Correlation analysis found that the flow experience had the an extremely significant correlation with the students' perceived usefulness, confirmation, satisfaction and continuous intention of VRLs. Presumably, due to the differences in flow experience of male students and femals, the difference of students' perceptions of virtual experiment experience was statistically significant by gender. Besides, the online learning experience had significant impact on the confirmation. The possible explanation was that the students' who had online learning experience had more appropriate expectations of VRLs and were more likely to meet their expectations.

Last but not the least, the study found that both perceived usefulness and satisfaction were important predictors of the students' continuance intention, which was consistent with Bhattacherjee's finding. What's more, flow experience was also a positive predictor of the students' continuance intention, which was also confirmed in Esteban-Millat's study. According to Esteban-Millat's study, positive affect, such as feeling happy, satisfied and cheerful, was the direct positive consequences of the flow experience in 
online learning environment [32]. Obviously, the better the students' flow experience was, the more satisfied they felt, and the stronger their continuance intention was.

\section{Conclusion and Implication}

According to above findings, there are several implications to share in integrating VRLs into teaching practice of engineering and scientific education.

It is significant to improve the students' flow experience in virtual experimental learning. On the one hand, the instructors need to improve the students' skills to match the challenges of the virtual experiments, especially for those high-level difficulty ones. On the other hand, the design and quality of the virtual experiments need be improved. More user-friendly interface design and more detailed experimental process guidance were strongly advised. At the same time, the realism of the simulation and the diversity of the interaction need to be promoted in the future development. Both the Augmented Reality and Mixed Reality were good choice to solve the problems.

It was essential to improve the students' satisfaction in the virtual experimental experience. Most previous studies only paid attention to assess the students' learning effectiveness but ignored their virtual experimental experience. With the prevailing of online course, especially the MOOCs, online experimental learning was going to be adopted widely in engineering and scientific education. It was essential to improve the students' satisfaction in the virtual experimental experience. It determined that when it was not mandatory, whether the students would prefer and experience the VRLs and continue to use it as a way of experimental learning. Of course, the potential factor that affect students' virtual experimental experience need to be further explored in future studies.

\section{Acknowledgement}

This work was supported by a grant from Research Project of Hubei Provincial Department of Education (Q20171205).

\section{References}

[1] Dormio, S. (2004). Control learning: present and future. Annual Reviews in Control, 28:115136.

[2] Koretsky, M., Kelly, C., \& Gummer, E. (2011). Students' perceptions of learning in the laboratory: comparison of industrially situated virtual laboratories to capstone physical laboratories. Journal of Engineering Education, 100:540-573. https://doi.org/10.1002/j. 2168-9830.2011.tb00026.x

[3] Gustavsson, I., Nilsson, K. \& Zackrisson, J. et al. (2009). On objectives of instructional laboratories, individual assessment, and use of collaborative remote laboratories. IEEE Transactions on Learning Technologies, 2: 263-274. https://doi.org/10.1109/tlt.2009.42 
[4] Sun, K., Lin, Y., \& Yu, C. (2008). A study on learning effect among different learning styles in a web-based lab of science for elementary school students. Computers \& Education, 50:1411-1422. https://doi.org/10.1016/j.compedu.2007.01.003

[5] Abdulwahed, M., \& Nagy, Z. K. (2011). The Trilab, a novel ICT based triple access mode laboratory education model. Computers \& Education, 56: 262-274. https://doi.org/10.1016/ j.compedu.2010.07.023

[6] Hennessy, S., Wishart, J. \& Whitelock, D. et al. (2007). Pedagogical approaches for technology-integrated science teaching. Computers \& Education, 48: 137-152. https://doi. org/10.1016/j.compedu.2006.02.004

[7] Potkonjak,V., Gardner, M., \& Callaghan, V., et al. (2016). Virtual Laboratories for Education in Science, Technology, and Engineering: a Review. Computers \& Education, 95:306327. https://doi.org/10.1016/j.compedu.2016.02.002

[8] Harward,V., del Alamo, J. \& Lerman, S. et al.(2008). The iLab shared architecture: a web services infrastructure to build communities of internet accessible laboratories. Proceedings of the IEEE, 96: 931-950. https://doi.org/10.1109/jproc.2008.921607

[9] Lowe, D., Murray, S., Lindsay, E., \& Liu, D. (2009). Evolving remote laboratory architectures to leverage emerging internet technologies. IEEE Transactions on Learning Technologies, 2(4), 289-294. https://doi.org/10.1109/tlt.2009.33

[10] Dormido, R., Vargas, H. \& Duro, N. et al. (2008). Development of a web-based control laboratory for automation technicians: the three-tank system, IEEE Transactions on Education, 51:35-44. https://doi.org/10.1109/te.2007.893356

[11] Koretsky, M., Amatore, D., Barnes, C., \& Kimura, S. (2008). Enhancement of student learning in experimental design using a virtual laboratory. IEEE Transactions on Education, 51(1): 76-85. https://doi.org/10.1109/te.2007.906894

[12] Restivo, M., Mendes, J., Lopes, A., \& Silva, C. et al. (2009). A remote laboratory in engineering measurement. IEEE Transactions on Industrial Electronics, 56(12): 4836-4843. https://doi.org/10.1109/tie.2008.2011479

[13] van Joolingen, W. R., de Jong, T., \& Lazonder, A. W. et al. (2005). Co-lab: research and development of an online learning environment for collaborative scientific discovery learning. Computers in Human Behaviour, 21(4): 671-688. https://doi.org/10.1016/j.chb. 2004.10.039

[14] Jara, C. A., Candelas, F. A., \& Torres, F. et al. (2009). Real-time collaboration of virtual laboratories through the internet. Computers \& Education, 52(1): 126-140. https://doi.org/ 10.1016/j.compedu.2008.07.007

[15] Jara, C. A., Candelas, F. A., \&Torres, F. et al. (2009). Synchronous collaboration of virtual and remote laboratories. Computer Applications in Engineering Education, 20(1): 124-136. https://doi.org/10.1002/cae.20380

[16] Lindsay, E., \& Good, M. (2005). Effects of laboratory access modes upon learning outcomes. IEEE Transactions on Education, 48(4): 619-631. https://doi.org/10.1109/te.2005. $\underline{852591}$

[17] Tzafestas, C., Palaiologou, N., \& Alifragis, M. (2006). Virtual and remote robotic laboratory: comparative experimental evaluation. IEEE Transactions on Education, 49(3): 360369. https://doi.org/10.1109/te.2006.879255

[18] Nickerson, J. V., Corter, J. E., \& Esche, S. K., et al. (2007). A model for evaluating the effectiveness of remote engineering laboratories and simulations in education. Computers \& Education, 49(3): 708-725. https://doi.org/10.1016/j.compedu.2005.11.019

[19] Abdulwahed, M., \& Nagy, Z. K. (2009). Applying Kolb's experiential learning cycle for laboratory education. Journal of Engineering Education, 98(3): 283-294. https://doi.org/ $\underline{10.1002 / j .2168-9830.2009 . t b 01025 . x}$ 
[20] Kollöffel, B., \& Jong, T. D. (2013). Conceptual Understanding of Electrical Circuits in Secondary Vocational Engineering Education: Combining Traditional Instruction with Inquiry Learning in a Virtual Lab. Journal of Engineering Education, 102(3):375-393. https://doi.org/10.1002/jee.20022

[21] Marques M. A., Viegas M. C., Costa-Lobo M. C. et al. (2014). How Remote Labs Impact on Course Outcomes: Various Practices Using VISIR. IEEE Transactions on Education, 57(3):151-159. https://doi.org/10.1109/te.2013.2284156

[22] Garcia-Zubia, J. , Cuadros, J. , \& Romero, S. et al. (2016). Empirical Analysis of the Use of the VISIR Remote Lab in Teaching Analog Electronics. IEEE Transactions on Education, 40:1-8. https://doi.org/10.1109/te.2016.2608790

[23] Raman, R., Achuthan, K., \& Nedungadi, P., et al. (2014). The VLAB OER Experience: Modeling Potential-Adopter Student Acceptance. IEEE Transactions on Education, 57(4):235-241. https://doi.org/10.1109/te.2013.2294152

[24] Koretsky, M., Kelly, C., \& Gummer, E. (2011). Student perceptions of learning in the laboratory: comparison of industrially situated virtual laboratories to capstone physical laboratories [J]. Journal of Engineering Education, 100(3): 540-573. https://doi.org/10.1002/ j.2168-9830.2011.tb00026.x

[25] Shin, N. (2010). Online learner's 'flow' experience: an empirical study. British Journal of Educational Technology, 37:705-720. https://doi.org/10.1111/j.1467-8535.2006.00641.x

[26] Oliver, R. L. (1980). A Cognitive Model for the Antecedents and Consequences of Satisfaction. Journal of Marketing Research, 17: 460-469.

[27] Bhattacherjee, A. (2001). Understanding Information Systems Continuance: An Expectation-Confirmation Model. MIS Quarterly, 25:351-370. https://doi.org/10.2307/3250921

[28] Csikszentmihalyi, M. (1975). Beyond boredom and anxiety: Experiencing flow in work and play. San Francisco, CA: Jossey-Bass.

[29] Trevino, L. K. \& Webster, J. (1992). Flow in Computer-Mediated Communication: Electronic Mail and Voice Mail Evaluation and Impacts. Communication Research, 19: 539-573. https://doi.org/10.1177/009365092019005001

[30] Estebanmillat, I., Martínez-López, J. F. \& Huertas-García, R. et al. (2014). Modelling students' flow experiences in an online learning environment. Computers \& Education, 71:111123. https://doi.org/10.1016/j.compedu.2013.09.012

\section{Authors}

Muhua Zhang is working as a lecture at college of computer and information technology, China Three Gorges University, Yichang, China. She got her doctor degree in Zhejiang University in 2016. Her current area of research are e-Learning, Learning Analytics, Open and Distant Education.

Yanyan Li is a professor in School of Educational Technology, Beijing Normal University, Beijing, China. She is also the director of Center for Knowledge Engineering of Beijing Normal University. Her research interests involve in Computer supported Collaborative Learning (CSCL), Learning Analytics, Personalized and Adaptive Learning, e-Learning and Semantic Web.

Article submitted 2019-05-05. Resubmitted 2019-06-17. Final acceptance 2019-06-19. Final version published as submitted by the authors. 